\title{
Integrated Supplementary Task-based Games
}

\author{
Hadi Maghsoud ${ }^{1, *}$ \\ ${ }^{1}$ Faculty of Foreign Languages and Literatures, University of Tehran, Tehran, Iran \\ *Correspondence: Faculty of Foreign Languages and Literatures, University of Tehran, Tehran, Iran. E-mail: \\ hadi.maghsoud@gmail.com
}

Received: April 4, 2018

Accepted: May 11, 2018 Online Published: July 15, 2018

doi:10.5430/ijelt.v5n2p43

URL: https://doi.org/10.5430/ijelt.v5n2p43

\begin{abstract}
This article explored the background for task-based games and how they could best fit in educational contexts to make use of their potential benefits for language teaching and learning purposes. First, the assumptions of task-based language teaching (TBLT) and game-based learning (GBL), as the two underlying theories of task-based games, were touched upon. It was suggested that pedagogical tasks could be used as a framework for designing educational games. The benefits and pitfalls of implementation of TBLT and GBL were also investigated. Moreover, it was argued that supplementary educational games that are in line with the syllabus rather than games used as the main means of instruction could result in more efficient teaching and learning. Finally, task-based games were posited as a powerful educational tool to utilize the merits and to compensate for the shortcomings of TBLT and GBL.
\end{abstract}

Keywords: task-based language teaching, game-based learning, task, educational games, task-based games

\section{Task-Based Language Teaching (TBLT)}

As the name might suggest, task-based language teaching, or TBLT (also known as task-based instruction) is a framework that utilizes tasks as the central unit for syllabus design, instruction and assessment. TBLT is closely associated with communicative language teaching (CLT). Emergence of CLT in the late 1960s triggered a paradigm shift away from a structure-based and towards a meaning-based approach to language teaching emphasizing features such as active learning, cooperative learning, fluency, learner needs, Focus on Form, using authentic materials, learner autonomy, and integration of skills (e.g., Richards, 2006). Whong (2011, pp. 134, 135) indicated that "with CLT as an approach, a teacher must look elsewhere for specific methods for teaching" and since "TBLT sits well not only with the basic tenets of CLT but with the generalizations that have emerged from research in SLA", it can work as a vehicle by which the principles of CLT and the latest findings SLA find the chance of implementation.

TBLT draws on psycholinguistic and sociolinguistic theories of SLA. The subcategories of each theory that are closely tied to TBLT are Input Hypothesis (Krashen, 1982), Output Hypothesis (Swain, 1985), Interaction Hypothesis (Long, 1981, 1983), Noticing Hypothesis (Schmidt, 1990), and mediation (Lantolf, 2000; Vygotsky, 1978), Zone of Proximal Development (ZPD) (Vygotsky, 1978), scaffolding (Wood, Bruner, \& Ross, 1976) respectively.

\subsection{Task}

Task, as the core element of TBLT, has been defined in different ways in the literature. For example, Prabhu (1987), one of the advocates of TBLT, defined task as "an activity which require[s] learners to arrive at an outcome from given information through some process of thought, and which allow[s] teachers to control and regulate that process." According to Lee (2000), a task is "(1) a classroom activity or exercise that has: (a) an objective obtainable only by interaction among participants, (b) a mechanism for structuring and sequencing interaction, and (c) a focus on meaning exchange; (2) a language learning endeavor that requires learners to comprehend, manipulate, and/or produce the target language as they perform some set of work plans." Bygate, Skehan, and Swain (2001) defined task as "an activity which requires learners to use language, with emphasis on meaning, to attain an objective." Ellis $(2009,2014)$ provides a comprehensive definition of tasks. He describes tasks as meaning-oriented activities with information gaps that involve learners in using their own resources to achieve linguistic and non-linguistic outcomes. In line with the underlying theories of TBLT, tasks, as a means of mediation, provide learners with comprehensible 
input and opportunities for production and negotiation of meaning in pairs or groups based on available language resources. In addition to fluency, tasks enable learners to approximate their interlanguage to target forms through noticing and feedback from peers or the teacher.

\subsection{Task Classification}

Tasks can be categorized as focused or unfocused. In the former, there is no preplanned linguistic feature as the purpose of the task and language is dealt with holistically. However, in the latter, the task is supposed to help learners learn one or some particular features such as a number of words or a grammatical structure. Another classification is based on the language skills involved in a task. Input-providing tasks require listening and reading, whereas output-providing tasks require speaking and writing.

Different typologies of tasks have been proposed in the literature. Ellis (2003) puts approaches to classifying tasks into four groups: (1) pedagogic; (2) rhetorical; (3) cognitive; and (4) psycholinguistic.

1. Pedagogic Classification: Ellis (2003) mentions a pedagogic classification offered by Gardner and Miller (1996). In this classification, tasks focus on discrete language components and skills and provide a means of integrating tasks into traditional modes of language teaching. This runs counter to the holistic language learning nature of tasks. Another classification was proposed by Willis (1996) which is based on the textbook activities learners are required perform:

1). Listing: tasks that involve brainstorming, fact-finding with a completed list as an outcome.

2). Ordering and sorting: tasks that involve sequencing, ranking, categorizing, and classifying items.

3). Comparing: tasks that involve similarities and differences

4). Problem-solving: tasks that require intellectual and reasoning powers to solve problems and puzzles.

5). Sharing personal experiences: tasks that encourage learners to talk freely about themselves and their experiences.

6). Creative tasks: these tasks are projects in that they involve combinations of listing, ordering and sorting, comparing, and problem solving tasks. In addition, such tasks might involve out-of-class research and team-work.

Rhetorical Classification: this classification includes tasks which serve as vehicles to teach different discourse types (i.e., narratives, instructions, description, reports, etc.) and genres (i.e., recipes, political speeches, job application letters, newsletters, medical consultations, etc.) regarding their organization, linguistic properties and functions. Rhetorical classification of tasks lends itself to courses for specific (particularly academic) purposes since it is in line with the needs of learners.

Cognitive Classification: this classification is concerned with the required cognitive operations in each task. Prabhu (1987) identified three types of tasks based on cognitive demand on learners:

1). Information-gap activity: this involves "a transfer of given information from one person to another - or from one form to another, or from one place to another - generally calling for the decoding or encoding of information from or into language" (ibid. 46). For example, learners receive only half of information (e.g., on a train station timetable) and exchange information in pairs to arrive at the complete information.

2). Reasoning-gap activity: this involves "deriving some new information from given information through processes of inference, deduction, practical reasoning, or a perception of relationships or patterns" (ibid. 46). For example, learners are required to find out a teacher's timetable from a number of class timetables. This activity goes beyond information comprehension and transfer in that there is an added reasoning element compared to information-gap activity. Thus, the exchanged information is different from that which was initially received.

3). Opinion-gap activity: this involves "identifying and articulating a personal preference, feeling, or attitude in response to a given situation" (ibid. 47). Story completion and discussion of a social issue are among examples of this activity. The activity may involve using facts and arguments to support one's opinion. There is no predetermined right or wrong response in such tasks since they are based on individuals' opinions.

Psycholinguistic Classification: a psycholinguistic classification of tasks was proposed by Pica, Kanagy, and Falodun's (1993). Their classification is psycholinguistic in that it draws on interactional categories that influence input comprehension, feedback, and output modification (as the underpinnings of the Interaction Hypothesis) (Ellis, 2003).

Richards and Rogers (2001) distinguished tasks based on: a) one-way or two-way information exchange; b) having one goal (convergent) or many goals (divergent); c) collaboration or competition among learners; d) having either 
one or multiple outcomes; e) concrete or abstract language use; f) simple or complex cognitive processing; g) simple or complex linguistic demand; and h) reflecting real-world or pedagogical activities.

\subsection{Task-based Lesson Design}

Different designs have been offered for a task-based lesson, however, it can be said that all of them include three phases of pre-task, during-task and post-task (Ellis, 2003). It needs to be mentioned that task phases are referred to with different names in the literature, for example, Nunan (2004) uses pre-task phase, a task-proper phase and a follow-up phase.

The Pre-task Phase: this phase engages learners in preparatory activities and sets the stage for the main task. The pre-task phase performs the function of schema-raising. It also directs the learners to the task, motivates them, and provides them with language required for the completion of the main task (Nunan, 2004). Ellis (2003) refers to four ways of preparing learners cognitively and linguistically in the pre-task phase: (1) performing a task similar to the main task; (2) seeing a model for task performance; (3) participating in non-task activities; and (4) strategic planning.

The During-task Phase: In this phase, the leaners complete the main task. Ellis (2003) elaborates on two groups of options at teachers' disposal regarding how the main task is implemented. The first set of options, called 'task performance options', are decided by the teacher before the task is performed. Task performance options are characterized as deciding on setting time pressure, allowing learners to access to the input (e.g., in a spot-the-difference tasks the input must be available but in a retelling story task the availability of the input is optional), and introducing a surprise element. The second set is 'process options' that are choices made by the teacher and learners while the task is being performed. Process options refer to the language learning beliefs and behaviors that the teacher and learners bring to the context of classroom. Task performance is highly affected by individuals' expectations of teaching and learning; i.e., whether the teacher and learners have a traditional form-focused or task-based mindset.

The Post-task Phase: this phase may entail answering questions about the task, telling the class about the conclusion of the task, and corrective feedback on errors that occurred during performing the main tasks (Nunan, 2004). Ellis (2003) identifies three major goals for the post-task phase: (a) task repetition, (b) reflection on task performance, and (c) focus on forms. In repeating a task, to add variety and also to make the task more challenging, the learners could be asked to perform the task in different groups or to have a public presentation. Reflection on task performance could involve asking learners to provide an oral or written report about the task process and conclusion, to give their opinions about how their performance can be improved, and to evaluate the task. Alternatively, the teacher can draw learners' attentions to incorrect forms in their speech and gaps in their knowledge. This is to make sure that the learners develop both fluency and accuracy in L2 at the same time. Willis and Willis (2007) points out three reason for a focus on form as the last phase of a task. First, learners can have a better understanding of the new forms they have been exposed to during the previous phases. Second, it increases the saliency of the new forms so that learners can notice them highly likely in the future. Third, it motivates learners in that they can make a better sense of what they have learnt and increases the likeliness of using the new form in their speech.

\section{Game-based Learning (GBL)}

While the word game might connote leisure, computer games have been used for educational purposes for many years in different fields, e.g., mathematics (Ke, 2013), ecology (Villalta et al., 2011), history (Huizenga et al., 2009), medicine (Rosenbaum, Klopfer \& Perry, 2006) biology (Brom, Preuss \& Klement, 2011), and art (Manero et al., 2015). Specifically speaking, in the field of first and second language teaching, games have been used as a facilitator in areas, to name a few, such as vocabulary learning (Smith et al., 2013), reading comprehension, (Homer et al., 2013), intercultural communicative competence (Guillén-Nieto \& Aleson-Carbonell, 2012).

The growth of game-based learning (GBL) could be attributed to many factors. Educational games contextualize learning, challenge individuals, allow production, strengthen problem-solving skills, motivate, encourage collaboration, foster deep learning and allow recreation of oneself (Gee, 2003). Videogames as new approaches to teaching could help learners left behind by traditional methods (Virvou, Katsionis \& Manos, 2005). In the same way, they could benefit learners with styles different from the ones mainly addressed in the classroom.

In his book, Gee (2003) discusses 36 learning principles that are involved in games. Here, I will only mention a limited number of them, which I assume, are more relevant to language learning.

1. Active, critical learning: learners are actively involved in the task of learning. They are not only the receivers of 
knowledge.

2. Psychosocial moratorium: Learners can take risks and use the feedback from failures to progress.

3. Identity: Learners develop identities with authority to make decisions

4. Self-Knowledge: in addition to learning about the domain, learners learn about themselves and their potentials.

5. Probing principle: Learning is a cycle of probing, reflecting, and forming a hypothesis; then retesting the hypothesis to accept or revise it.

6. Practice: learners practice more in a context that is not monotonous.

7. Situated meaning: learners learn better when meanings are contextualized.

8. Multimodality: learners learn through different modalities (e.g., sounds, images, texts, etc.)

9. Explicit information on-demand and just-in-time: The learner receives explicit information when he/she needs it and can understand and use it.

10. Discovery: overt guidance is kept at minimum and learners discover things by themselves.

11. Cultural models: since we take new identities, we are open to new cultural models.

12. Insider principle: The learner is an "insider," "teacher," and "producer" and not just a "consumer."

\section{Task-based Games}

Tasks have gained widespread popularity in pedagogy in the last two decades; however, integration of technology in language teaching is still an area that has not been utilized sufficiently while it started at around at the same time as TBLT (Thomas \& Reinders, 2010). Concerning GBL, there are some reasons that have prevented it from receiving sufficient attention in language education. In majority of cases in the literature, the idea of game-based learning (GBL) is augmented at the expense of and as a replacement for conventional classroom practices (e.g. DeHaan, Reed \& Kuwada, 2010; Guillén-Nieto \& Aleson-Carbonell, 2012; Hwang et al., 2015). This claim is strengthened by a tendency among researchers to use games in classrooms as the main medium of instruction. However, GBL may not be an efficient instructional method on its own. In fact, the idea of viewing serious games and conventional methods as two rivals from whom only one must deserve survival might be misleading and redundant. As Mayer (2016) argues "[p]olicy implications are to use games for targeted learning objectives, align games with classroom activities, not confuse liking with learning, and use games to maintain challenge". In other words, it is recommended that serious games be considered as a supplement and not a stand-alone method.

Secondly, studies regarding language learning mostly focus on a single subskill. It might be assumed that, for example, a game targeting vocabulary of a function leaves the other subskills to carry out the function to be addressed by other means of teaching. This fragmented and discrete-point approach fails to accompany the learner to the intended final language product all through a game or a series of games.

Moreover, although games such as Mingoville, a language learning web-based game for children, have a series of activities to aid language learning, they seem to have such pitfalls as being disconnected with the flow of information in the classroom and the course book. Garris, Ahlers and Driskell (2002) argue that "if we pair instructional content with certain game features, we can harness the power of games to engage users and achieve desired instructional goals". This casts doubt on the efficiency of using already developed games for specific purposes. Therefore, where a game is to be used for education, it needs to be developed and tailored to suit the intended instructional purposes.

Several criticisms have also been levelled at TBLT. Ellis (2009) attributed such criticisms as vagueness of the concept of task, inadequate context for L2 learning, limited role of teachers, lack of theoretical foundation, insufficient coverage of grammar and lack of exposure to rich input to misunderstandings surrounding TBLT. However, he admitted that there are complicated problems that might impede the implementation of TBLT. In some educational contexts, there is a strong preference for gaining knowledge than developing skills, which is, up to some extent, at odds with TBLT. In such contexts, there is no place for performance-based testing and only knowledge is tested. In addition, sometimes, cultural beliefs about learning and education conflict with the claims of TBLT. More importantly, discipline problems and tremendous workload for teachers in large classes hinder the successful implementation of TBLT (even if the teachers were adequately trained in TBLT).

One solution to meet the challenges on the way to successful implementation of TBLT and GBL is amalgamation of them in the form of task-based games. Chapelle (2001) highlights the importance of integration of technology and 
TBLT.

... anyone concerned with second language teaching and learning in the 21 st century needs to grasp the nature of the unique technology-mediated tasks learners can engage in for language acquisition and how such tasks can be used for assessment. . . . To meet the challenge, the study of the features of computer-based tasks that promote learning should be a concern for teachers as well as for SLA researchers who wish to contribute to knowledge about instructed SLA (p. 2).

Task-based games could serve as a focal point for similar underlying principles of TBLT and GBL such as active learning or learning by doing, contextualized learning, information on-demand (FonF in TBLT), and discovery learning as well as different merits of each approach. The synergy of task-based games could be a powerful tool to pave the way for utilization of potentials from both approaches to facilitate SLA. The positive features of each approach also could complement and compensate for the shortcomings of the other.

As was mentioned previously, one major shortcoming of TBLT is cultural irresponsiveness. However, GBL does not suffer from cultural and educational barriers. In fact, people from different cultural and educational backgrounds relate to games. Additionally, TBLT could serve as a framework which helps overcome the deficiencies of implementation of GBL; i.e., failure to cover language skills and components in an integrated manner and lack of association with the curriculum.

Moreover, games have their own inbuilt system of automatized monitoring and assessment which makes exertion of external control (by a teacher) redundant. Such capacity of GBL can provide rich TBLT-based homework assignment for learners. Thus, task-based games could be considered as a solution in contexts where TBLT falls short. However, it should be noted that task-based games are not assumed to be a replacement for TBLT; but they are offered as a complement for the conventional TBLT. To clarify, a sketchy example of the possible outlook of a focused and input-providing task-based game is provided below.

In the pre-task phase, a number of words extracted from or related to the text (from the main task) alongside their definitions are presented. When the learners feel they have learnt the words, they go to the next stage of the pre-task phase. In this stage, the learners are tested to see whether they have learnt the definitions properly (e.g., by clicking numbered boxes corresponding to each word and not knowing which word is going to appear). Every time the learners match a definition with the right word they get a score and a positive feedback. Also, for every incorrect match, they lose a score but they receive a hint to help them choose the right match in the second try.

For the main task phase, learners read or listen to a passage. Before the task starts, the learners are asked one or two questions about the passage (which increases their curiosity and provides them with a sort of background as to the information presented in the passage). They are also instructed that they will be asked more questions about the passage after reading or listening to it (to draw their attention to the meaning of the passage). Then they are instructed to reply verbally some $w h$ questions with fixed answers.

In the post task phase, a prevalent grammatical structure is highlighted in the text (input enhancement). Then the learners answer some concept check multiple-choice questions about the structure and are required to mark the option which best describes the structure's function. After that, the learners find similar structures in the text and write them in boxes which equal to the structures in number. For each correctly identified structure, the learners receive a score. In the end, the learners record their voice summarizing the passage, giving their opinion about the passage, suggesting a solution for a problem in the passage, etc. and send it to the teacher for feedback (or the teacher assigns some learners randomly to talk about the passage in the class).

\section{Conclusion}

Task-base games could be a helpful and motivating supplement for language learners with different styles, interests and educational backgrounds. They could help experienced and inexperienced teachers in different educational systems make sure learners take care of their own learning outside the classroom. In addition, games provide contextualized and real-lifelike activities which results in better retention (Brom, Preuss, \& Klement, 2011) and transferability of the learnt material.

In sum, it seems reasonable to assume that a task-based game would

- foster autonomy

- promote motivation 
- enhance competitiveness

- provide a rich out-of-class activity

- enable learners form different cultures to relate to TBLT

- engage learners of different learning styles

- present a new means of providing feedback

- solve the problem of implementing TBLT in large classes

- help learners at different levels accomplish a task

- and bring variety to language classrooms.

\section{References}

Brom, C., Preuss, M., \& Klement, D. (2011). Are educational computer micro-games engaging and effective for knowledge acquisition at high-schools? A quasi-experimental study. Computers \& Education, 57(3), 1971-1988. https://doi.org/10.1016/j.compedu.2011.04.007

Bygate, M., Skehan, P., \& Swain, M. (Eds.). (2001). Researching pedagogic tasks: Second language learning, teaching, and testing. Harlow, England: Pearson.

Chapelle, C. (2001). Computer applications in second language acquisition: Foundations for teaching, testing and research. Cambridge: Cambridge University Press. https://doi.org/10.1017/CBO9781139524681

De Haan, J., Reed, W. M., \& Kuwada, K. (2010). The effect of interactivity with a music video game on second language vocabulary recall. Language Learning \& Technology, 14(2), 74-94.

Ellis, R. (2003). Task-based language learning and teaching. Oxford, England: Oxford University Press.

Ellis, R. (2009). Task-based language teaching: Sorting out the misunderstandings. International Journal of Applied Linguistics, 19(3), 221-246. https://doi.org/10.1111/j.1473-4192.2009.00231.x

Ellis, R. (2014). Taking the critics to task: The case for task-based teaching. Proceedings of CLaSIC, 103-117.

Gardner, D., \& Miller, L. (1996). Tasks for Independent Learning. TESOL Publications.

Garris, R., Ahlers, R., \& Driskell, J. E. (2002). Games, motivation and learning: a research and practice model. Simulation \& Gaming, 33(4), 441-467. https://doi.org/10.1177/1046878102238607

Gee, j. P. (2003). What video games have to teach us about learning and literacy. New York: Palgrave/St. Martin's.

Guillén-Nieto, V., \& Aleson-Carbonell, M. (2012). Serious games and learning effectiveness: The case of "It's a Deal!". Computers \& Education, 58(1), 435-448. https://doi.org/10.1016/j.compedu.2011.07.015

Homer, B. D., Kinzer, C. K., Plass, J. L., Letourneau, S. M., Hoffman, D., Bromley, M., Hayward, E. O. ,...Kornak Y. (2014). Moved to learn: The effects of interactivity in a Kinect-based literacy game for beginning readers. Computers \& Education, 74, 37-49. https://doi.org/10.1016/j.compedu.2014.01.007

Huizenga, J., Admiraal, W., Akkerman, S., \& ten Dam, G. (2009). Mobile game-based learning in secondary education: engagement, motivation and learning in a mobile-city game. Journal of Computer Assisted Learning, 25(4), 332-344. https://doi.org/10.1111/j.1365-2729.2009.00316.x

Hwanga, W. Y., Shihb, T. K., Mab, Z. H., Shadievc, R., \& Chenb, S. Y. (2015). Evaluating listening and speaking skills in a mobile game-based learning environment with situational contexts. Computer Assisted Language Learning, 1-19.

Ke, F. (2014). An implementation of design-based learning through creating educational computer games: A case study on mathematics learning during design and computing. Computers \& Education, 73, 26-39. https://doi.org/10.1016/j.compedu.2013.12.010

Krashen, S. D. (1982). Principles and practice in second language acquisition. Oxford, England: Pergamon Press.

Lantolf, J. (2000). Second language learning as a mediated process. Language Teaching Journal, 33, 79-96. https://doi.org/10.1017/S0261444800015329

Lee, J. (2000). Tasks and Communicating in Language Classrooms. New York: McGraw-Hill.

Long, M. (1981), Input, interaction, and second-language acquisition. In H. Winitz (Ed.), Native Language and 
Foreign Language Acquisition (pp. 259-278). Annals of the New York Academy of Science, 379. https://doi.org/10.1111/j.1749-6632.1981.tb42014.x

Long, M. (1983). Native speaker/non-native speaker conversation and the negotiation of comprehensible input. Applied Linguistics, 4, 126-41. https://doi.org/10.1093/applin/4.2.126

Manero, B., Torrente, J., Serrano, A., Martínez-Ortiz, I., \& Fernandez-Manjon B. (2015). Can educational video games increase high school students' interest in theatre? Computers \& Education, 87, 182-191. https://doi.org/10.1016/j.compedu.2015.06.006

Mayer, R. E. (2016). What Should Be the Role of Computer Games in Education? Policy Insights from the Behavioral and Brain Science, 1-7.

Nunan, D. (2004). Task-based language teaching. Cambridge: Cambridge University Press. https://doi.org/10.1017/CBO9780511667336

Pica, T., Kanagy, R., \& Falodun, J. (1993). Choosing and using communication tasks for second language instruction and research. In G. Crookes \& S. M. Gass (Eds.), Tasks and language learning: Integrating theory and practice (pp. 9-34). Clevedon, England: Multilingual Matters.

Prabhu, N. S. (1987). Second language pedagogy. Oxford: Oxford University Press.

Richards, J. C. (2006). Communicative language teaching today. New York: Cambridge University Press.

Richards, J. C., \& Rodgers, T. S. (2001). Approaches and methods in language teaching. Cambridge: Cambridge University Press. https://doi.org/10.1017/CBO9780511667305

Rosenbaum, E., Klopfer, E., \& Perry, J. (2007). On location learning: authentic applied science with networked augmented realities. Journal of Science Education and Technology, 16(1), 31-45. https://doi.org/10.1007/s10956-006-9036-0

Schmidt, R. (1990). The role of consciousness in second language learning. Applied Linguistics, 11, 129-158. https://doi.org/10.1093/applin/11.2.129

Smith, G. G., Li, M., Drobisz, J., Park, H. R., Kim, D., \& Smith, S. D. (2013). Play games or study? Computer games in eBooks to learn English vocabulary. Computers \& Education, 69, 274-286. https://doi.org/10.1016/j.compedu.2013.07.015

Swain, M. (1985). Communicative competence: Some roles of comprehensible input and comprehensible output in its development. In S. Gass \& C. Madden (Eds.), Input in second language acquisition (pp. 235-53). Cambridge, MA: Newbury House.

Thomas, M., \& Reinders (Eds.). (2010). Task-based language learning and teaching with technology. London, UK: Continuum.

Villalta, M., Gajardo, I., Nussbaum, M., Andreu, J.J., Echeverría A., \& Plass, J.L. (2011). Design guidelines for Classroom Multiplayer Presential Games (CMPG). Computers \& Education, 57, 2039-2053. https://doi.org/10.1016/j.compedu.2011.05.003

Virvou, M., Katsionis, G., \& Manos, K. (2005). Combining software games with education: evaluation of its educational effectiveness. Educational Technology \& Society, 8(2), 54-65.

Vygotsky, L. S. (1978). Mind in society: The development of higher psychological processes. Cambridge, MA: Harvard University Press.

Whong, M. (2011). Language teaching: Linguistic theory in practice. Edinburgh: Edinburgh University Press Ltd.

Willis, D., \& Willis, J. (2007). Doing task-based teaching. Oxford: Oxford University Press.

Wood, D., Bruner, J., \& Ross, G. (1976). The role of tutoring in problem-solving. Journal of Child Psychology and Psychiatry, 17, 89-100. https://doi.org/10.1111/j.1469-7610.1976.tb00381.x 